TAO, Vol. 15, No. 5, 1035-1060, December 2004

\title{
Coping with Dust Storm Events: Information, Impacts and Policymaking in Taiwan
}

\author{
Ho-Ching Lee ${ }^{1, *}$ and Chung-Ming Liư ${ }^{2}$ \\ (Manuscript received 16 October 2003, in final form 30 August 2004)
}

\begin{abstract}
Long-range transport of dust, from the deserts and sand lands of China and Mongolia, has recently become an emerging international environmental issue. Observations record an increase in the intensity and frequency of dust storm events and that the events occur earlier and are longer-lasting.

Among the dust storm events, were those, which transported elevated dust particles across the Pacific Ocean to reach North and South Korea, Japan, Taiwan and North America, including Canada and the United States. These events have a negative impact on public health, visibility, aviation and pollution. The pressing need to document dust episodes and to assess the associated impacts is now widely recognized. While most research focuses on atmospheric aspects of dust events, a better understanding of their wide-ranging impact and policy responses must also be properly addressed.

This paper adopts a conceptual framework for information collection and distribution, environmental impacts and policymaking. It draws on scientific research findings from the EPA's Intensive Monitoring Project on China's Dust Storms and examines how dust issues are raised and framed in the policymaking process. Given the frequency, intensity and impact of long-range transport dust events in Taiwan, this paper raises and discusses a set of policy options and recommendations relevant to this natural phenomenon.
\end{abstract}

(Key words: Dust storm events, Policy responses, Information, Impacts and policymaking)

\footnotetext{
${ }^{1}$ Center of General Education, Chung-Yuan Christian University, Chung-Li, Taiwan, ROC

2 Department of Atmospheric Sciences, National Taiwan University, Taipei, Taiwan, ROC

* Corresponding author address: Dr. Ho-Ching Lee, Center of General Education, Chung-Yuan Christian University, Chung-Li, Taiwan, ROC;E-mail: hoching@cycu.edu.tw
} 


\section{INTRODUCTION}

On March 12, 1995, a muddy downpour of rain, mixed with red sand and dust fell in the areas of XiZhi, JiLong, RuiFang, and YiLan in northern Taiwan. Local inhabitants thought that air pollutants released by the nearby power plant had caused the muddy rain. However, after investigations by the Environmental Protection Administration (EPA), it was soon realized that the red sand in the rain came from thousands of miles away, originating from the dust storms in the interior of China and transported to Taiwan via long-range transport. From this point on, people have started to focus more attention on the effects of China's dust storms on the regional air quality in Taiwan.

The term "dust storm" is used to describe a severe windstorm that sweeps clouds of dust across an extensive area, especially in an arid region. A typical dust storm usually reduces visibility to less than $1 \mathrm{~km}$. Extremely severe dust storms can reduce visibility to $50 \mathrm{~m}$ and are sometimes called "black-winds." Large-scale dust storms originating in northeastern China frequently occur at the end of winter and during the spring. Normally, the sand and dust swept up by the storms are transported to Japan and Korea, and only under unique climatic conditions will they affect Taiwan. However, due to desertification and global weather changes that have caused droughts in China, the frequency and the intensity of dust storms are clearly increasing. This means that sandstorms are now affecting Taiwan more often and their impact is more severe.

The purpose of this study was to identify and provide policy options and recommendations to cope with dust storm events in Taiwan and is one of the few attempts to explore policy perspectives on dust storm events. This study applied scientific findings from the EPA's Intensive Monitoring Project (IMP) on China's Dust Storms, assessed their impact and examined the emergence of the "dust storms" issue and the evolution of "dust events".

\section{UNDERSTANDING DUST STORM EVENTS}

Dust storms are complicated phenomenon, which involve meteorological, agricultural and geographical factors. Conditions for their formation, geological origins and transportation are complex and warrant a brief explanation.

\subsection{Conditions for the Formation of Dust Storms}

Dust storms are simply a combination of "dust" and "storms". Northwestern China hosts many deserts and is situated on the passageway of north Siberian arctic air as it enters China. In spring, around March, the surface soil thwarts and lays bare without cover. Combined with the still active arctic high-pressure system, this lay creates favorable conditions for dust storms to occur. Due to these special conditions, northern China is the major origin of dust storms.

\subsection{Geological Origin of Dust Storms}

Many dust storms originate from the dry and semi-dry areas, various deserts, bare-ground 
and cultivated grasslands of HwaBei. Of these, the $\mathrm{HeSi}$ corridor in GangSu and the AhLaSanMon area in Mongolia are major contributors. The TaKeLaMaGan desert and various farming areas along the MonSiaNine Great Wall section, as well as the grassland areas of Inner Mongolia, are referred to as the Four Major Dust Storms Origins of China (Fig. 1).

Dramatic increases in recent dust storm events are due mainly to the massive unplanned urban developments in China, which have contributed to the severe desertification of China, providing ever-increasing sources of sand from where dust storms originate. In the 50's and 60's, the desert area in China increased by 1560 square kilometers annually. In the 70's, the desert area increased by 2100 square kilometers annually, and for the past 20 years, the desert area has increased roughly by 2460 square kilometers each year.

Global climate change has also had significant effects on the formation of dust storms. Chinese,Besearchers have attributed, the frequency of dust storms, which invaded northern China in spring 2000 to widespread oceanic atmospheric changes of El Nino. The El Nino effect initiated strong-winds in winter 1999. In addition, the temperature was above average in spring 2002, and the amount of rainfall was significantly lower, causing the surface soil to be especially dry and porous when thwarted.

According to the statistics documented by the Chinese Academy of Sciences, dust storms in China occurred 5 times in the 50's, 8 times in the 60's, 10 times in the 70's, 14 times in the 80 's, and 17 times in the 90's. In 2000 alone, 12 dust storms occurred. Not only is there a trend for an increasing frequency of dust storms but also, for an increasing intensity (Fig. 2).

\subsection{Long Range Transportation of Dust Storms}

After a dust storm is formed, larger particles normally affect only the originating area or nearby areas, before sinking back to the ground. Smaller particles, on the other hand, can be transported vertically to 1000 to $3000 \mathrm{~m}$, and carried westward.

Except for China itself, dust storms mainly affect eastern areas such as Japan, Korea, the Pacific Ocean and Hawaii. They have been known to travel as far as western Canada and the USA and occasionally affect southern areas, such as Taiwan and even the Philippines.

Over the course of the dust storm's westward travel, some coarse particles sink back into the ground and some are washed down by rain or snow. Due to the dispersion effect, the further the sand travels, the less dense the concentration of sand is. When dust storms have traveled thousands of kilometers, the main effects they have on the local areas include a decrease in visibility and an increase of aerosol particles.

\subsection{Assessing the Impact on Taiwan Air Quality}

The earliest record of China's dust storms affecting air-quality of Taiwan was on April 12, 1988. Every air quality monitoring station north of JiaI, including HuaLian, detected a dramatic increase in the concentration of aerosol particles $\left(\mathrm{PM}_{10}\right)$. At the peak of the event, the concentration of $\mathrm{PM}_{10}$ (particulate matter with aerodynamic diameter less than $10 \mu \mathrm{m}$ ) measured was as high as 201 to $422 \mu \mathrm{g} \mathrm{m}^{-3}$. During a mud-rain event in March 1995, the WanLi station recorded a concentration as high as $586 \mu \mathrm{g} \mathrm{m}^{-3}$. Investigation of samples taken 


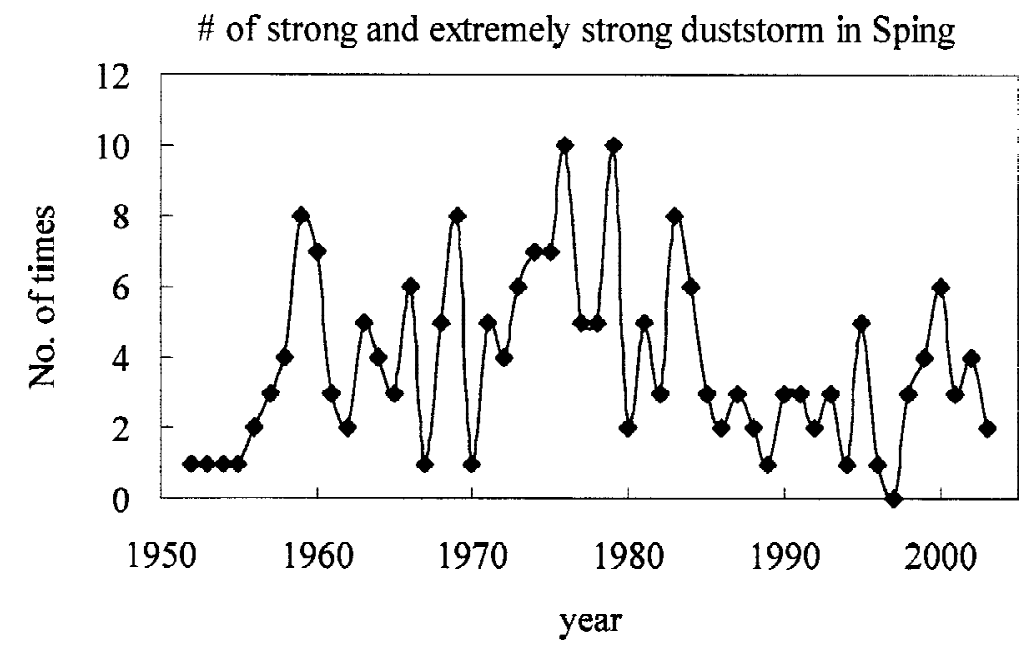

Fig. 1. Frequency of strong and extremely strong dust storms in Mainland China by year (spring).

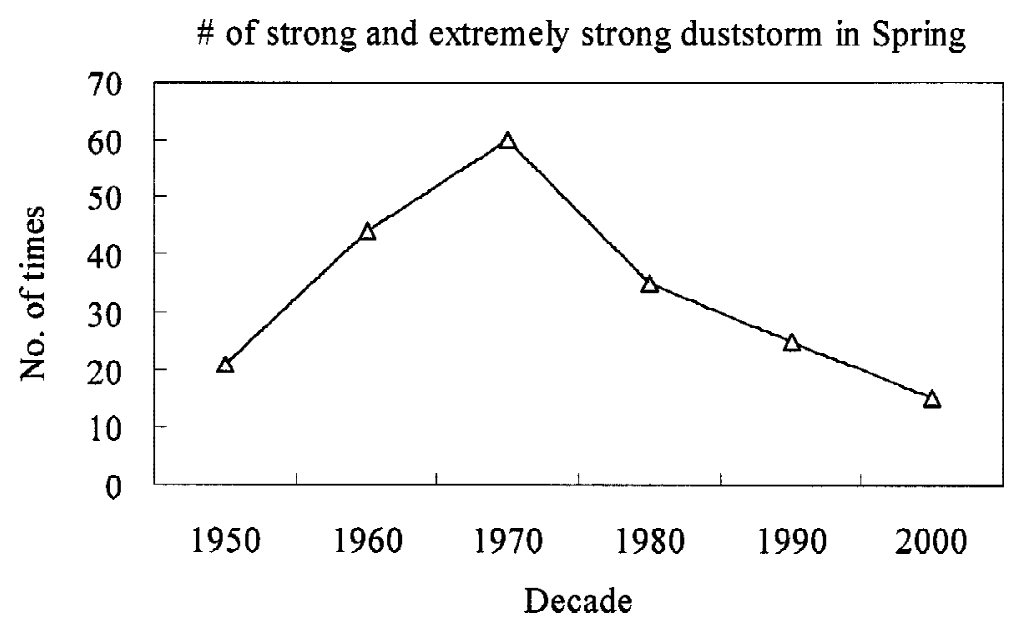

Fig. 2. Frequency of strong and extremely strong dust storms in Mainland China by decade (spring). 
from stations at JiLong and the XiZhi, during the event, revealed that the chemical compositions of the sand and dust were consistent with that of China's dust storms, and so supported the view that the dust storms originated in China.

When the dust storms started to affect Taiwan, stations in northern Taiwan revealed a dramatic increase in the concentration of fine airborne particles. For example, MaZu and YungMing stations normally read a concentration of airborne particles of $20 \mu \mathrm{g} \mathrm{m}^{-3}$. During the time dust storms hit Taiwan however, these readings jumped as high as 150 to $200 \mu \mathrm{g} \mathrm{m}^{-3}$. Since dust storms are wide-area events, they also traveled southward to central and southern Taiwan and have been known to affects areas as far east as HuaLian and TaiDong and as far south as HengChun.

The EPA has set up 72 air quality stations in Taiwan, which constitute the monitoring network. Over the years, this set up has dramatically increased the capacity to monitor and measure air-polluting events, caused by long range-transport dust storms from China. In recent years, there has been a clear trend for increased frequency and intensity of dust storms.

The number of times Taiwan was affected by dust storms has also increased. This increase has been particularly dramatic in recent years. Taiwan was affected by 5 dust storms in 2000, with the number increasing to 7 and 11 in 2001 and 2002, respectively (Liu and Lee 2003). The chart below (Fig. 3) illustrates this trend.

Number of Times Taiwan Was Affected by Sandstorms in Mainland China

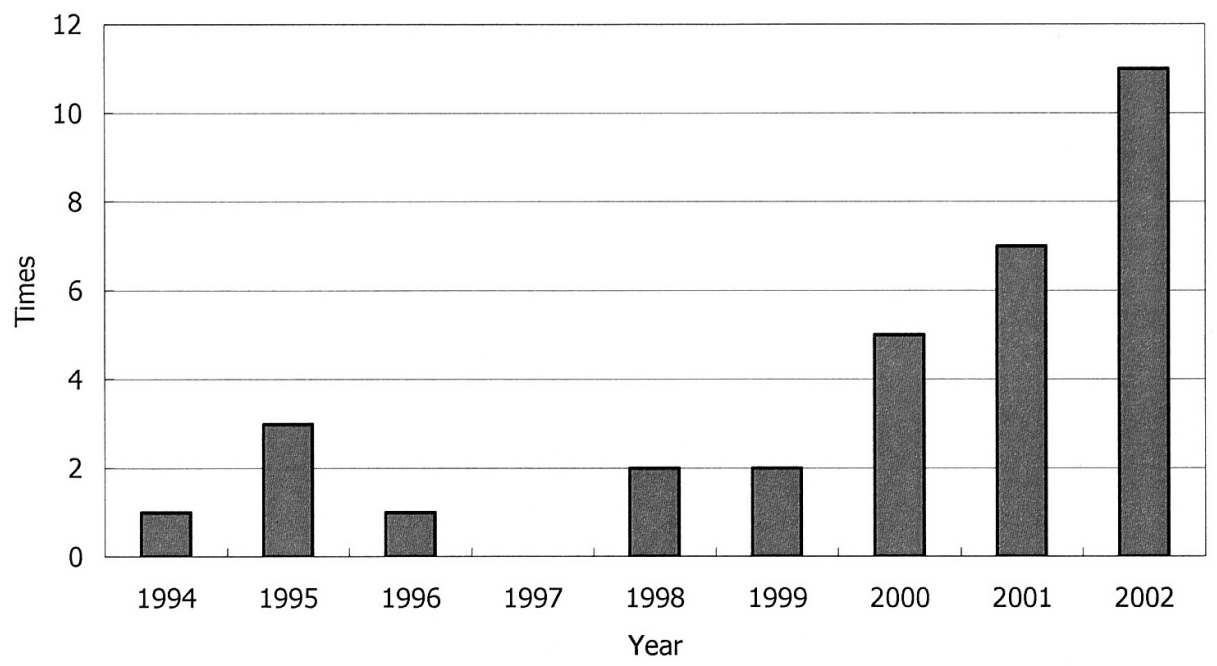

Fig. 3. Number of times Taiwan was affected by sandstorms from Mainland China.

(* excluding level 0 events) 


\subsection{Case Analysis 2002}

The absence of any dust event activity in 1997 has been followed by a sharp increase, with eleven events recorded in 2002. The high frequency of dust events in 2002 was subject to detailed analysis by Liu and Lee (Liu and Lee 2003). In their analysis, the duration of the events were recorded and predictions, from NAAPS, were compared with actual effects recorded at monitoring stations. The local air quality impact was also assessed and a leveling system introduced to standardize the grading of the effects of dust events in Taiwan.

Given the high number of recorded events during the year and the innovation of a standardized grading system, this study marked a significant moment in the serious study and analysis of the dust event phenomenon in Taiwan. The case analysis table of this study is included as Table 1 (adapted from Liu and Lee 2003).

\subsection{Precursor Background Stations}

To monitor and measure dust storm events, stations in MaZu, WanLi and YangMing were used as precursor background stations. For each event, there was usually correlation between the NAAPS forecast duration and that duration period observed and measured locally. In some cases, local contributions to events were not readily distinguishable and this should be kept in mind when considering impact analysis.

These three background stations were selected because they are relatively free of local aerosols, such as sea salt and carbon dioxide. Located in a remote area, near the northern tip of Taiwan, WanLi has been considered the primary site. This location is also upwind during the northeastern monsoons.

The pollution standard index (PSI) was applied to identify the level of each dust storm event. Level 1 denotes PSI < 150; Level 2, 150 to 200; Level 3, 300 to 400; Level 5, > 500. IMP (Intensive Monitoring Project), established this grading system from research findings. The grading system can be credited with advanced monitoring analysis of dust storm events. The highest reading for the period is generally used because a time delay is possible due to the geographical movement of the impact of a dust event.

PSI data was recorded between 1am and 12am on the same day and PS2 data was collected over alternate $12 \mathrm{hr}$ periods, from $12 \mathrm{pm}$ to $12 \mathrm{pm}$. PS2 data was gathered to provide comprehensive data of the dust event, particularly at night. Often events have a short duration, which can be easily overlooked when relying solely on PS1 data sets.

\subsection{Ten Year Monitoring Program}

A detailed study of the intensity of dust events was conducted over a ten-year period, between 1994 and 2003 (Liu 2003). This data has proved invaluable in the analysis of dust event phenomenon for Taiwan and was a groundbreaking scientific research program that produced the first significant long-term data set for dust events. Data collection was focused on WanLi, MaZu and YangMing, but that obtained from additional monitoring stations (72 in total around Taiwan) were also included. 
Table 1. The case analysis table of 2002 dust storm events.

\begin{tabular}{|c|c|c|c|c|c|c|}
\hline Case & $\begin{array}{l}\text { Duration } \\
\text { (LT) }\end{array}$ & $\begin{array}{l}\text { NAAPS } \\
\text { Simulation } \\
\text { Predicted } \\
\text { Effected } \\
\text { Duration } \\
\text { (LT) } \\
\end{array}$ & $\begin{array}{l}\text { Station } \\
\text { Recorded } \\
\text { Effected } \\
\text { Duration } \\
\text { (LT) }\end{array}$ & $\begin{array}{l}\text { Local Air Quality lmpact } \\
\text { (LT) }\end{array}$ & $\begin{array}{l}\text { Average } \\
\text { of } 3 \text { most } \\
\text { significan } \\
\text { t data } \\
\text { entries } \\
\left(\mu \mathrm{g} / \mathrm{m}^{3}\right) \\
\end{array}$ & Level \\
\hline 1 & $\begin{array}{c}2001 / 12 / 2 \\
9(14) \sim \\
12 / 31 \\
(14)\end{array}$ & $\begin{array}{l}1 / 1(20) \sim \\
1 / 3(08)\end{array}$ & $\begin{array}{l}1 / 1(12) \sim \\
1 / 3(08)\end{array}$ & $\begin{array}{c}\text { 1/1: WanLi (22) } \\
\text { XinZhuang (23) } \\
\text { ChungZan (23) } \\
\text { 1/2: WanLi (23) } \\
\text { XiZhi(21) TsaiLiao (20) }\end{array}$ & $\begin{array}{l}1 / 1: 173 \\
1 / 2: 153\end{array}$ & $\begin{array}{l}1 \\
1\end{array}$ \\
\hline 2 & $\begin{array}{c}1 / 4(14) \sim \\
1 / 6(14)\end{array}$ & $\begin{array}{l}1 / 7(20) \sim \\
1 / 11(20)\end{array}$ & $\begin{array}{c}1 / 7(12) \sim \\
1 / 8(24) \\
\end{array}$ & $\begin{array}{l}\text { 1/7: XiZhi (20) ChungZan } \\
\text { (20), ShiLin (20) }\end{array}$ & $1 / 7: 159$ & 1 \\
\hline 3 & $1 / 18(14)$ & $\begin{array}{l}1 / 21(14) \sim \\
1 / 24(08)\end{array}$ & $\begin{array}{l}1 / 20(12) \\
\sim 1 / 22(8)\end{array}$ & $\begin{array}{c}\text { 1/21*: WanLi (21) } \\
\text { TsaiLiao (18) HsingDian } \\
\text { (20) }\end{array}$ & $1 / 21: 157$ & 1 \\
\hline 4 & $\begin{array}{c}2 / 7(08) \sim \\
2 / 9(08)\end{array}$ & $\begin{array}{l}2 / 10(20) \sim \\
2 / 15(14) \\
2 / 18(02) \sim \\
2 / 19(02)\end{array}$ & $\begin{array}{l}2 / 9(2) \sim \\
2 / 10(8) \\
2 / 11(12) \\
\sim 2 / 12(8)\end{array}$ & $\begin{array}{c}\text { 2/9: ShiLin (10) } \\
\text { XinZhuang (11) XiZhi } \\
(10) \\
\text { 2/11: ChungZan (22) } \\
\text { XinZhuang (24) WanLi } \\
\text { (22) } \\
\end{array}$ & $\begin{array}{c}2 / 9: 237 \\
2 / 11: 327\end{array}$ & $\begin{array}{l}2 \\
3\end{array}$ \\
\hline 5 & $\begin{array}{c}3 / 4(14) \sim \\
3 / 6(14)\end{array}$ & $\begin{array}{l}3 / 6(08) \sim \\
3 / 11(02)\end{array}$ & $\begin{array}{c}3 / 5(12) \sim \\
3 / 7(8) \\
3 / 8(12) \\
3 / 9(8)\end{array}$ & $\begin{array}{l}\text { 3/6: WanLi (23) TsaiLiao } \\
\text { (17) XiZhi (18) } \\
\text { 3/8: HuaLian (19) } \\
\text { ChungZan (14) } \\
\text { XinZhuang (17) }\end{array}$ & $\begin{array}{c}<150 \\
3 / 8: 161\end{array}$ & $\begin{array}{l}0 \\
1\end{array}$ \\
\hline 6 & $\begin{array}{c}3 / 13(8) \sim \\
3 / 16(8)\end{array}$ & $\begin{array}{l}3 / 18(2) \sim \\
3 / 20(20)\end{array}$ & $\begin{array}{c}3 / 16(6) \sim \\
3 / 19(8)\end{array}$ & $\begin{array}{c}\text { 3/16: WanLi (16) XiZhi } \\
\text { (16) ZanAi (19) } \\
\text { 3/18 ChungZan (24) } \\
\text { XiZhi (24) WanLi (22) } \\
\text { (3/19 West coast pollution } \\
\text { level increases, with the } \\
\text { most significant increase } \\
\text { in PMIO particles) }\end{array}$ & $\begin{array}{c}<150 \\
3 / 18: 160\end{array}$ & $\begin{array}{l}0 \\
1\end{array}$ \\
\hline 7 & $\begin{array}{c}3 / 19(14) \\
\sim 3 / 22 \\
(14) \\
\end{array}$ & $\begin{array}{l}3 / 22(20) \sim \\
3 / 25(2)\end{array}$ & $\begin{array}{c}3 / 22 \\
(12) \sim 3 / 23 \\
(24) \\
\end{array}$ & $\begin{array}{l}\text { 3/23: ZanAi (17), Wanli } \\
\text { (17) ChungZan (17) }\end{array}$ & $<150$ & 0 \\
\hline 8 & $\begin{array}{l}3 / 27(14) \\
\sim 3 / 29(8)\end{array}$ & $\begin{array}{l}3 / 30(8) \sim \\
4 / 2(14) \\
4 / 4(2) \sim \\
4 / 4(20)\end{array}$ & NA & $\begin{array}{l}\text { No evidence suggesting } \\
\text { any impact. The pollution } \\
\text { might have been washed } \\
\text { away by rain before } \\
\text { reaching Taiwan. }\end{array}$ & & \\
\hline 9 & $\begin{array}{l}4 / 5(14) \sim \\
3 / 10(14)\end{array}$ & $\begin{array}{c}4 / 8(20) \sim \\
4 / 14(8)\end{array}$ & $\begin{array}{l}4 / 8(12) \sim \\
4 / 10(24)\end{array}$ & $\begin{array}{c}\text { 4/9: WanLi (15) XiZhi } \\
\text { (17) ZanAi (16) } \\
\text { 4/10: WanHwa (8) WanLi } \\
\text { (6) XinZhuang (9) }\end{array}$ & $\begin{array}{c}4 / 9: 204 \\
4 / 10: 183\end{array}$ & $\begin{array}{l}2 \\
1\end{array}$ \\
\hline 10 & $\begin{array}{c}4 / 15(14) \\
\sim 4 / 17 \\
(14) \\
\end{array}$ & $\begin{array}{l}4 / 17(14) \sim \\
4 / 19(20)\end{array}$ & $\begin{array}{c}4 / 17 \\
(12) \sim 4 / 18 \\
(24) \\
\end{array}$ & $\begin{array}{l}\text { 4/17: WanLi }(21) \\
\text { 4/18*: WanHwa (8) } \\
\text { ZanAi (6) XiZhi }(7)\end{array}$ & $<150$ & 0 \\
\hline 11 & $\begin{array}{c}5 / 21(14) \\
\sim 5 / 22 \\
(14)\end{array}$ & $\begin{array}{l}5 / 24(8) \sim \\
5 / 27(2)\end{array}$ & $\begin{array}{l}5 / 23(8) \sim \\
5 / 24(24)\end{array}$ & $\begin{array}{c}\text { 5/23: WanLi (22) } \\
\text { 5/24 : WanLi (7) ZanAi } \\
\text { (11) ChungZan (7) }\end{array}$ & $<150$ & 0 \\
\hline
\end{tabular}

* Need to consider local contribution

Level: $0:<150 ; 1: 150 \sim 200 ; 2: 200 \sim 300 ; 3: 300 \sim 400 ; 4: 400 \sim 500 ; 5: 500$ and above (Adopted from Liu and Lee 2003). 
The date and time of the maximum level at WanLi was recorded for each dust event that occurred. For those events that lasted more than $24 \mathrm{hrs}$, or occurred during the midnight date change, the maximum level for each day was also recorded. The average maximum level was calculated as an average over the three principal stations, WanLi, MaZu and YangMing. Again this was calculated for each day that the dust event occurred. The level was recorded as PS1, using the grading system, from 1 to 5 , as outlined above.

PS1 and PS2 peaks over 100 were counted and recorded for all 72 stations in north Taiwan for each day of the event duration. For example, Dust Event \#7 occurred over two days, peaking on March 12 and 13 at 18:00 hrs and 01:00 hrs respectively. The average maximum level for the three stations on March 12 was a PS1 of 588 (Level 5) and on March 13, a PS1 of 290 (Level 2). On the first day of the event, 12 stations in north Taiwan had a PS1 greater than 100. On the second day no stations recorded PS1 greater than 100. Similarly, on March12, 19 stations recorded a PS2 greater than 100, but none recorded such a high level on the second day of the event. The data for each day of the dust events monitored during the ten-year program are depicted in Table 2.

\subsection{Assessing Background Monitoring Station Data}

For the period 1994 - 2003, 42 dust events affected air quality in northern Taiwan area, an average of 4.2 events per annum. However, the actual number of events per annum varies per each year, from 0 to 8 (see Fig. 4). To take note, the number of dust events used here is in fact excluding level 0 events.

Using average/mean concentration derived from the three stations, a five tier grading system was developed, with Level 1 being the lowest and Level 5 the highest. $82 \%$ of the dust events were graded at Level 1 or 2. The average level during the period was 1.87 (see Fig. 5).

The highest number of events occurred in March, with $28 \%$ or 15 events occurring in that month. The data indicated a steady rise in the number of events from January to a peak in March and a reduction in the number thereafter to May (See Fig. 6).

\subsection{PS1 Dataset}

PS1 is an index for average air quality data taken between $1-24 \mathrm{hr}$, of the same day. The total number of days when the air quality was affected by dust storms was 54 , or a mean average of 5.4 days per year. Of these, there were $37 \%$ or 20 days when PS1 was greater than 100. This equates to two days per year on average, when PS1 was greater than 100 in 16.2 stations (See Fig. 7). The most severe impact occurred in 2000, when a total of six days showed a PS1 reading greater than 100 at 84 stations.

\subsection{PS2 Dataset}

Since dust events also take place at night, PS2 was used as a quasi-index, using readings from noon to noon. It is crucial to incorporate this data alongside the standard PS1 data, as events may have short duration and can be overlooked if data were only collected during the day. 
For the period 1994 - 2003, there were 15 days when PS2 was greater than 100, or 1.5 days on average per year. This equates to $28 \%$ measured at an average of 15.7 stations. As for PS1 data, the year 2000 was the most severe, with four days recording PS2 greater than 100 at 55 stations. When the dust event level was equal to, or greater than, Level 2 this corresponded to a greater number of PSI (PS2) days recorded at more stations. The reverse was also the case. In addition, the majority of days, with PS1 (PS2) greater than 100, took place in March and April. (See Fig. 8)

Table 2. Monitoring analysis at WanLi station: 1994 - 2003.

\begin{tabular}{|c|c|c|c|c|}
\hline $\begin{array}{l}\text { Dust } \\
\text { Event }\end{array}$ & $\begin{array}{l}\text { Local Time of } \\
\text { maximum level at } \\
\text { WanLi }\end{array}$ & $\begin{array}{c}\text { Maximum level as an } \\
\text { average of the three } \\
\text { stations (shown as } \\
\mu \mathrm{g} / \mathrm{m}^{3} \text { (Level)) }\end{array}$ & \begin{tabular}{|c|} 
Number of stations \\
in north Taiwan \\
where PSI $>100$
\end{tabular} & $\begin{array}{c}\text { Number of stations } \\
\text { in north Taiwan } \\
\text { where PS2 }>100\end{array}$ \\
\hline 1 & 1994/1/27 01LT & $185(1)$ & 0 & 0 \\
\hline 2 & 1994/2/9 12LT & $298(2)$ & 3 & 0 \\
\hline 3 & 1994/2/21 22LT & $179(1)$ & 0 & 0 \\
\hline 4 & 1994/3/24 17LT & $171(1)$ & 0 & 0 \\
\hline 5 & 1995/2/28 15LT & $212(2)$ & 1 & 14 \\
\hline 6 & 1995/3/4 12LT & $209(2)$ & 0 & 0 \\
\hline 7 & $\begin{array}{l}\text { 1995/3/12 18LT } \\
1995 / 3 / 1301 \mathrm{LT}\end{array}$ & 588 (5) $290 \quad(2)$ & 120 & 190 \\
\hline 8 & $\begin{array}{l}\text { 1995/5/14 23LT } \\
1995 / 5 / 1501 \mathrm{LT}\end{array}$ & $270(2) 239(2)$ & 02 & 10 \\
\hline 9 & $\begin{array}{c}1996 / 5 / 823 \mathrm{LT} \\
1996 / 5 / 912 \mathrm{LT} \\
1996 / 5 / 10 \text { 02LT } \\
1996 / 5 / 12 \quad 10 \mathrm{LT}\end{array}$ & $\begin{array}{c}341 \text { (3) } 306(3) 172(1) \\
162(1)\end{array}$ & 02400 & 261500 \\
\hline 10 & 1997/1/2 03LT & $252(2)$ & 0 & 0 \\
\hline 11 & 1999/1/7 10LT & $260(2)$ & 1 & 0 \\
\hline 12 & 1999/1/15 19LT & $171(1)$ & 0 & 0 \\
\hline 13 & 1999/2/3 021LT & $193(1)$ & 1 & 0 \\
\hline 14 & 1999/2/12 16LT & $156(1)$ & 0 & 0 \\
\hline 15 & 1999/2/19 11LT & $212(2)$ & 0 & 0 \\
\hline 16 & $\begin{array}{l}\text { 1999/4/6 17LT } \\
\text { 1999/4/7 12LT }\end{array}$ & 324 (3) 211 (2) & 15 & 81 \\
\hline 17 & 1999/4/13 12LT & $167(1)$ & 0 & 0 \\
\hline 18 & $2000 / 2 / 2621 \mathrm{LT}$ & $214(2)$ & 0 & 0 \\
\hline 19 & $2000 / 3 / 2006 \mathrm{LT}$ & $214(2)$ & 0 & 0 \\
\hline 20 & $\begin{array}{l}2000 / 3 / 24 \text { 15LT } \\
2000 / 3 / 25 \text { O2LT }\end{array}$ & 336 (3) 252 (2) & 184 & 230 \\
\hline 21 & $2000 / 3 / 2910 \mathrm{LT}$ & $274(2)$ & 19 & 7 \\
\hline 22 & $\begin{array}{l}2000 / 4 / 1020 \mathrm{LT} \\
2000 / 4 / 1101 \mathrm{LT}\end{array}$ & 220 (2) 179 (1) & 00 & 00 \\
\hline 23 & $\begin{array}{l}2000 / 4 / 2713 \mathrm{LT} \\
2000 / 4 / 2802 \mathrm{LT}\end{array}$ & 555 (5) 565 (5) & 2119 & 240 \\
\hline 24 & $2000 / 5 / 112 \mathrm{LT}$ & $268(2)$ & 3 & 0 \\
\hline
\end{tabular}


Table 2. Continued.

\begin{tabular}{|c|c|c|c|c|}
\hline $\begin{array}{c}\text { Dust } \\
\text { Event }\end{array}$ & $\begin{array}{l}\text { Local Time of } \\
\text { maximum level } \\
\text { at WanLi }\end{array}$ & $\begin{array}{c}\text { Maximum level as an } \\
\text { average of the three } \\
\text { stations (shown as } \\
\mu \mathrm{q} / \mathrm{m}^{3} \text { (Level)) }\end{array}$ & \begin{tabular}{|c|} 
Number of \\
stations in north \\
Taiwan where \\
PSI $>100$
\end{tabular} & $\begin{array}{l}\text { Number of } \\
\text { stations in north } \\
\text { Taiwan where } \\
\text { PS2 }>100\end{array}$ \\
\hline 25 & $\begin{array}{l}2000 / 5 / 1323 \mathrm{LT} \\
2000 / 5 / 1401 \mathrm{LT}\end{array}$ & $196(1) 199$ (1) & 00 & 01 \\
\hline 26 & $2001 / 1 / 1413 \mathrm{LT}$ & $237(2)$ & 3 & 0 \\
\hline 27 & $2001 / 2 / 114 \mathrm{LT}$ & $177(1)$ & 0 & 0 \\
\hline 28 & $2001 / 2 / 1618 \mathrm{LT}$ & $289(2)$ & 0 & 0 \\
\hline 29 & $2001 / 3 / 212 \mathrm{LT}$ & $196(1)$ & 1 & 1 \\
\hline 30 & $2001 / 3 / 412 \mathrm{LT}$ & $334(3)$ & 6 & 3 \\
\hline 31 & $2001 / 3 / 710 \mathrm{LT}$ & 204 (2) & 0 & 0 \\
\hline 32 & $2001 / 3 / 2812 \mathrm{LT}$ & $264(2)$ & 0 & 0 \\
\hline 33 & $2001 / 4 / 1209 \mathrm{LT}$ & $338(3)$ & 13 & 15 \\
\hline 34 & $\begin{array}{l}2002 / 1 / 122 \mathrm{LT} \\
2002 / 1 / 219 \mathrm{LT}\end{array}$ & $173(1) 153(1)$ & 00 & $\overline{00}$ \\
\hline 35 & $2002 / 1 / 720 \mathrm{LT}$ & 159 (1) & 0 & 0 \\
\hline 36 & $2002 / 2 / 1122 \mathrm{LT}$ & 327 (3) & 5 & 13 \\
\hline 37 & $2002 / 3 / 815 \mathrm{LT}$ & $161(1)$ & 0 & 0 \\
\hline 38 & $2002 / 3 / 1822 \mathrm{LT}$ & $160(1)$ & 0 & 0 \\
\hline 39 & $\begin{array}{c}2002 / 4 / 915 \mathrm{~L} \\
2002 / 4 / 1008 \mathrm{~L}\end{array}$ & 204 (2) 218 (1) & 00 & 00 \\
\hline 40 & $2003 / 1 / 2311 \mathrm{LT}$ & $166(1)$ & 0 & 0 \\
\hline 41 & $2003 / 2 / 2008 \mathrm{LT}$ & $175(1)$ & 0 & 0 \\
\hline 42 & $2003 / 3 / 2207 L T$ & $172(1)$ & 0 & 0 \\
\hline
\end{tabular}

Source: Adapted from (Liu 2003).

\subsection{Event Peaks and Proximity}

Events in March 2003 occurred in close time proximity, being only 1 - 2 days apart. In YangMing, the lowest concentration occurred on June 4, 1999 and highest concentration occurred on December 3, 1995.

Figure 9 shows data, from 42 events, obtained at WanLi station. The local time for the highest $\mathrm{PM}_{10}$ measurement was set as time zero (the peak recorded $\mathrm{PM}_{10}$ presence) and $\mathrm{PM}_{10}$ measured 2 days prior to the event was compared with that measured 4 days after the event. Based on $\mathrm{PM}_{10}$ data sets at WanLi station, most events were single-peak and some events showed a double peak within 24 hours. In addition there were cases, where a second and even a third peak was demonstrated, after the first, with an interval time of $1-2$ days. Over all however, most events were single-peak and the highest concentration average was $214 \mu \mathrm{g} \mathrm{m}^{-3}$. 


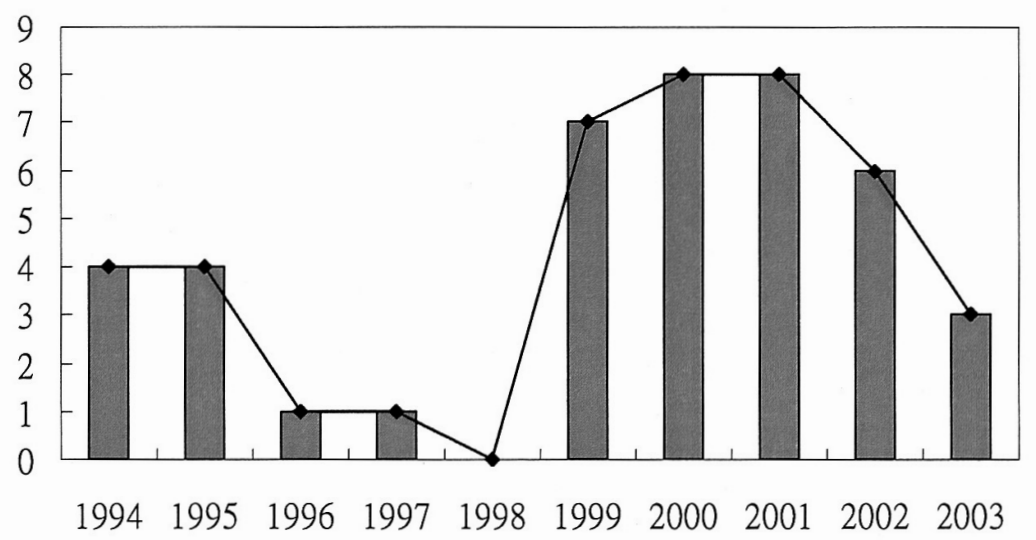

Fig. 4. Number of dust events affecting Taiwan per year in 1994 - 2003.

(* excluding level 0 events)

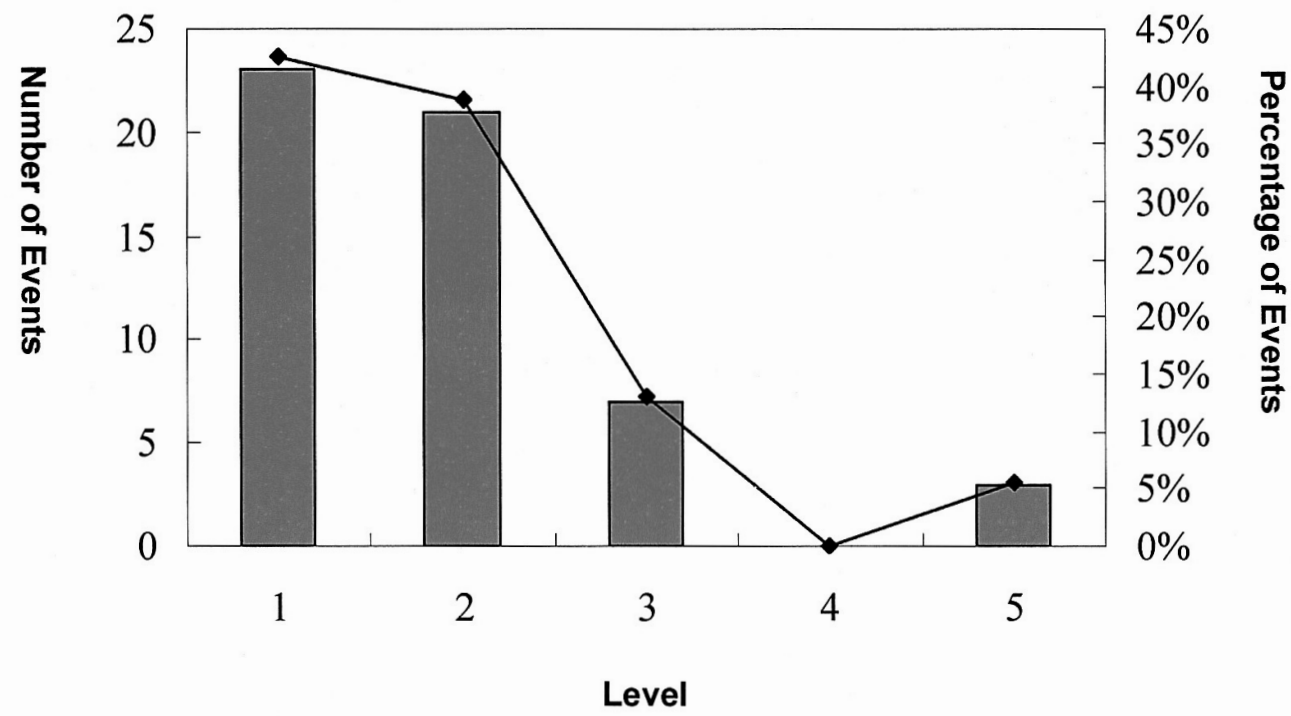

Fig. 5. Distribution of dust events by level in $1994-2003$.

The 42 events at WanLi were re-examined with the occurring local time set as time zero, and compared with $\mathrm{PM}_{10}$ measured $12 \mathrm{hrs}$ before and $12 \mathrm{hrs}$ after the event. $15-25 \%$ of events that took place showed a PS1 greater than 100. In other words, about $70 \%$ of events had 


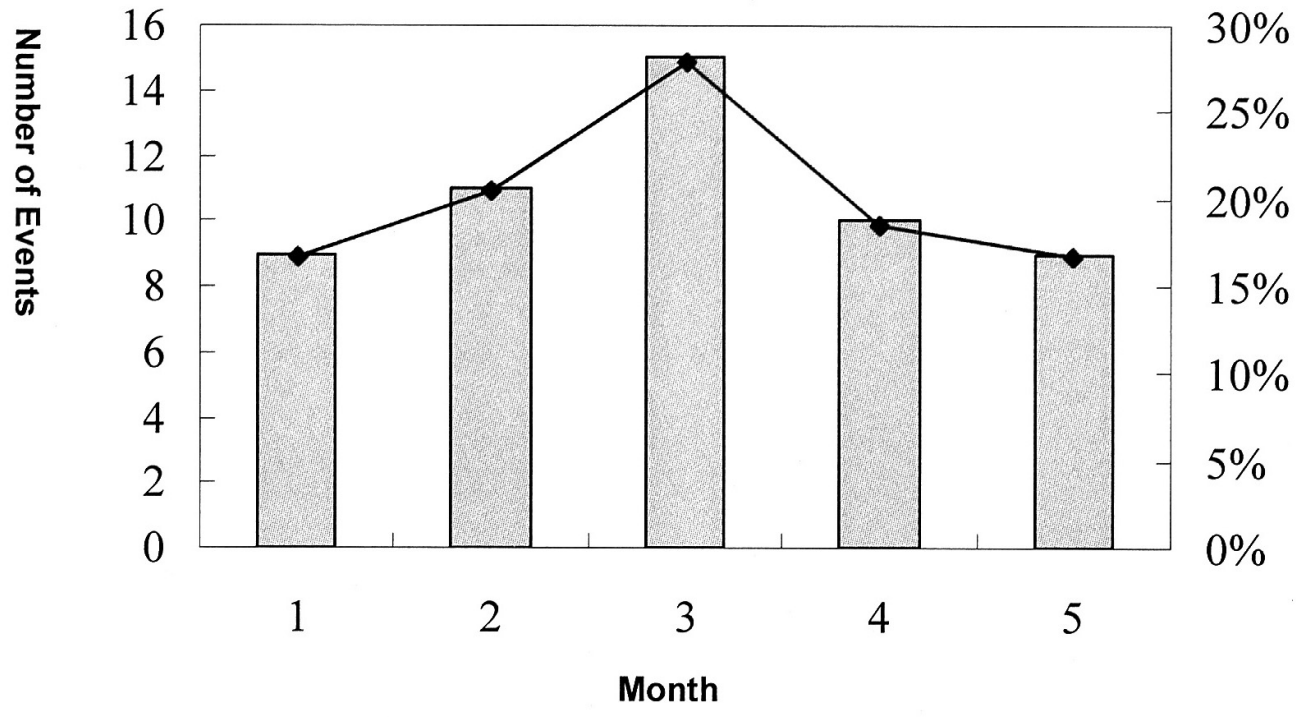

Fig. 6. Distribution of dust events by month in 1994 - 2003.

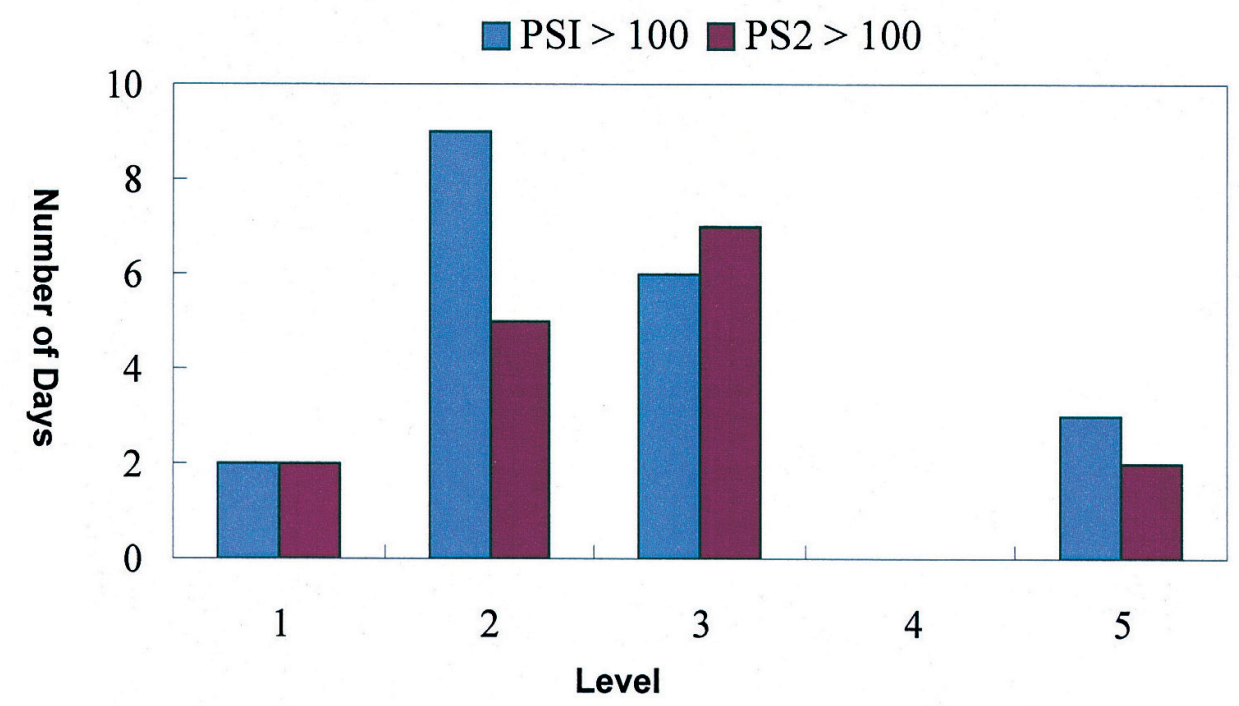

Fig. 7. Comparison of PS1 and PS2 level analysis in 1994 - 2003. 


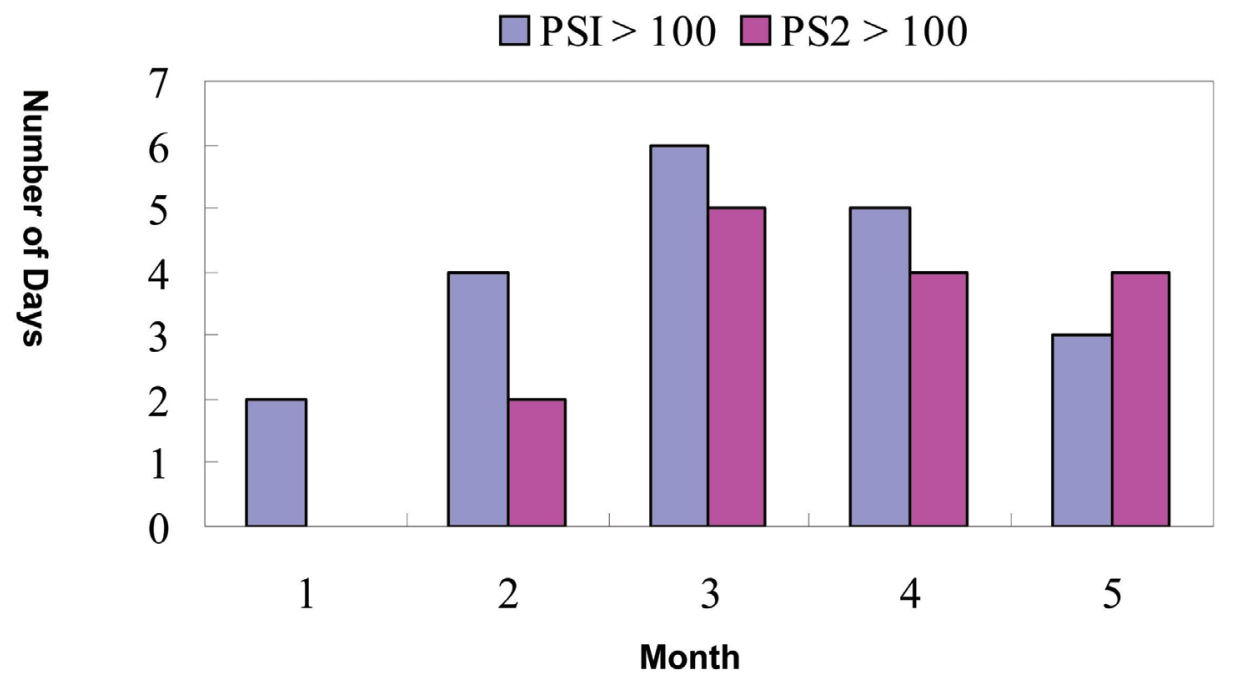

Fig. 8. Distribution of PS1 and PS2 level assessment by month in $1994-2003$.

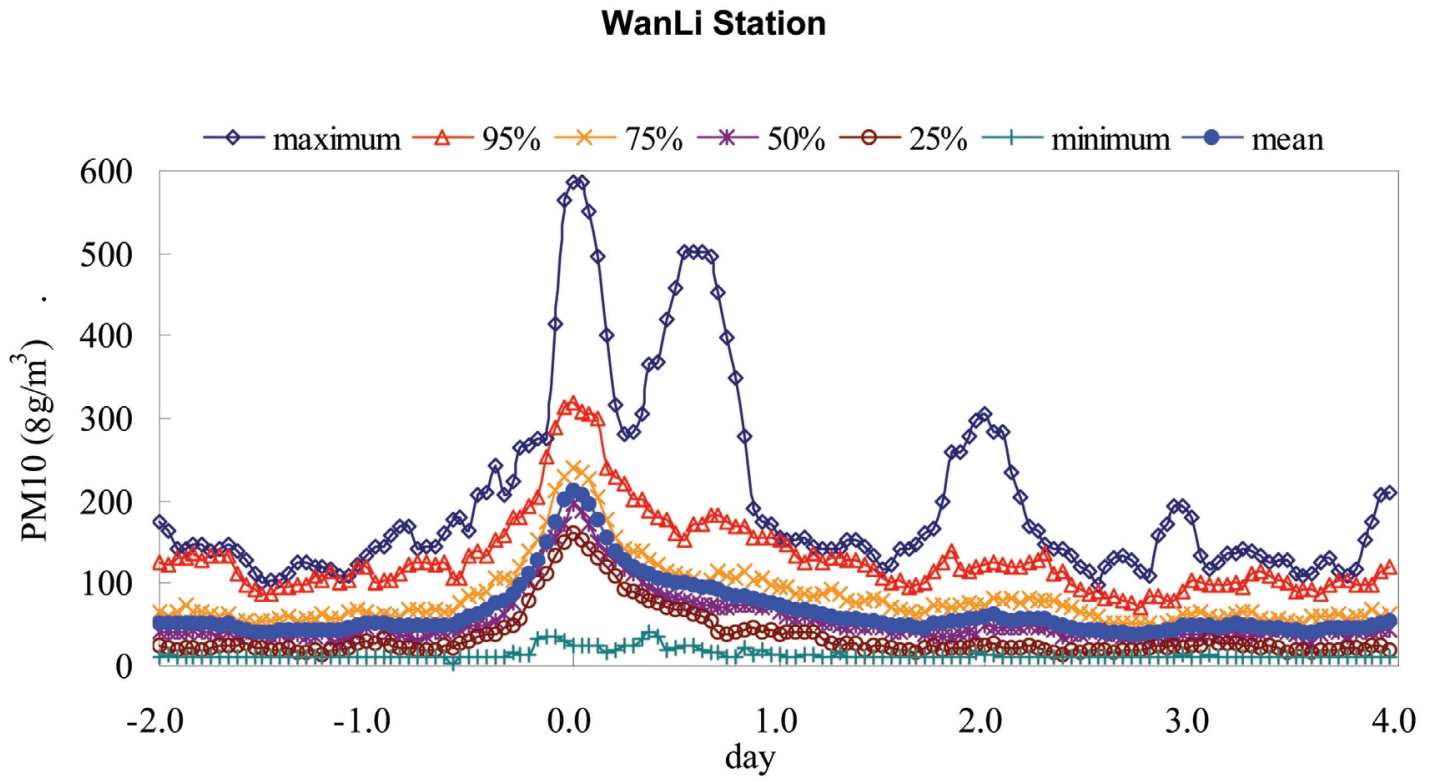

Fig. 9. Cumulative concentration of aerosol particles over time during dust events at Wanli station. 
a PS1 less than 100 even though they were affected by the long-transport dust storm from Mainland China. A PS1 greater than 100 was more likely to be found at the LanLi, ZenAi, TsaiLiao, XiZhi, XinZhaug, GuTing, ZhongShan, Dai Yuan, GuanYin, HuKou, XinZhu stations (See Fig. 10).

\subsection{Geographical Distribution of Dust Storm Events}

Taking a 95\%, 85\%,75\% and 50\% average, Fig. 10 shows that the northern coastal area was most likely to be affected by dust events, with gradual involvement of the south and the east. In south TaiZhong (Central Taiwan) the chance of measuring an event with a concentration level greater than of $150 \mu \mathrm{g} \mathrm{m}^{-3}$ was less than $50 \%$, while in the south of Tai-dong and Pin-dong, the chance of doing so was zero.

A typical dust event begins affecting Taiwan $12 \mathrm{hrs}$ before its peaks. After peaking, it has usually withdrawn fully within 36 hours. The lag time for the central/southern/eastern region is $6 / 12 / 6$ hours respectively after the peak.

\subsection{Impacts on Public Health}

Dust storms affect air-quality by increasing the aerosol concentration. Poor air quality places an added stress on body and eco systems. Dust storms also have a negative impact on agriculture, by disrupting photosynthesis and damaging crops. In addition, fine aerosol particles in the dust storms reflect sunlight, and in so doing affect the process by which ground soil absorbs sunlight and evaporates water. The physical and chemical composition of clouds also dramatically changed.

The impact of dust events on local air quality and public health are of the greatest concern in Taiwan. The most severe case on record is that of the mud-rain incident, in March 1995, in northern Taiwan. Since high concentrations of aerosol particles are known to stress the respiratory system, people with respiratory and cardiovascular diseases need to be especially careful during dust storm events. When long range-transport dust storms hit Taiwan, an increased concentration of aerosol particles has also caused the number of allergy cases to rise and an increase in symptoms such as coughing, asthma, irritated eyes, and sensitive and itchy skin. Sick leave due to respiratory symptoms are more frequent now, and the number of clinical treatments for respiratory symptoms has also increased.

The health impact study under the IMP, found that the number of emergency visits to National Taiwan University Hospital and ShinGuang Memorial Hospital rose within 1 to 3 days after a dust storm event. From data collected during a sandstorm event in 2002, Chang (2002) found that not only did visits increase, but also that the effects were "more significant for children aged 0-6 with mild upper-respiratory illness." The event also affected cardiac patients who showed "significant increases in the coagulator factor of $t P A$ and inflammatory marker of hs-CRP" along with "decreases in heart rate variability $(H R V)$ " during the period (Chang 2002). A panel of allergy patients also demonstrated a significant increase in various markers indicating a worsening of diseases. The results from this preliminary study indicate that further research into the health affects of dust storms is warranted. 

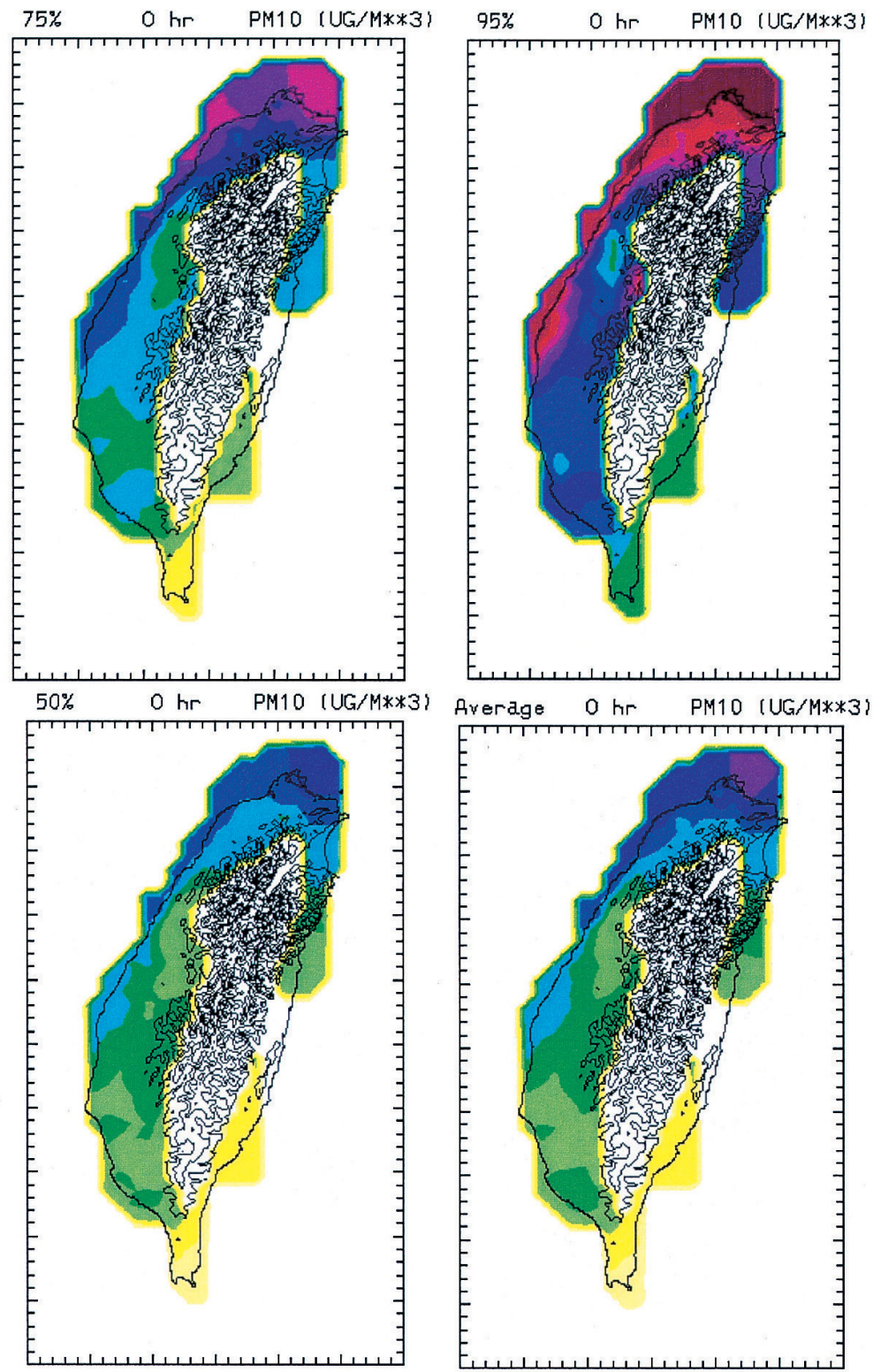

Fig. 10. Geographical distribution of the effect of dust events in Taiwan. 


\subsection{Environmental Impact}

Recent research has indicated the presence of bio-aerosols and organic microbes in dust event affected air (Chao and Chan 2003). The study specifically looked at the introduction of foreign micro-organisms to Taiwan as a result of dust storms in China. Bio-aerosol levels were monitored before, during and after each dust storm period at the EPA's designated sampling locations. Higher levels of Aspergillus, Aureobasidium, Chaetomium, and Yeast were found during dust storm periods. Rare fungi, including Botrysporium, Rhinocladiella, Trichothecium, were only recovered during dust storm periods. Fungal spore levels did not increase during the dust period. However a positive association with $\mathrm{PM}_{2.5}$ (particulate matter with an area diameter of less than $2.5 \mu \mathrm{m}$ ) implies that dust storm sands are fungi carriers.

Baseline data was also established by taking monthly samples in the Taipei area. This baseline data showed the most prevalent fungi included non-sporulating fungi,Cladosporium, Penicillium, Aspergillus, Curvularia, Fusarium, Alternaria, Botrytis, Arthrinium, and Coelomycetes. Fungal levels were associated with a variety of air pollutants and meteorological factors.

Even though the magnitude of China's dust storms in 2003 were not as intense as in other years significant increases in certain fungi were found to indicate that foreign microorganisms were carried by dust storms. Environmental monitoring and exposure assessment should be conducted to further evaluate the effects of dust storms on public health and the ecology in Taiwan. Currently research is being undertaken to investigate the prevalence of viruses associated with dust incursions from China, including Tuberculosis and controversially, the SARS virus.

\section{COPING WITH DUST STORM EVENTS}

\subsection{Natural Phenomena as Focusing Events}

When natural phenomena turn into natural disasters; policymakers and the public simultaneously become aware of these rare but sudden and damaging events (called focusing events). Focusing events are often important elements of the policy making process, because they attract local and/or national attention, mobilize the media, and trigger policy responses. (Kingdon 1995; Birkland 1997). This is not to say that focusing events are the sole catalyst in policy development. Other scholars also consider the roles of social and economic changes to be important in policy and politics. More specifically, problem structure associated with uncertainty of scientific information could also play a critical role in environmental policymaking. (Lee 2004; Mitchell et al. 2005)

It may seem intuitive to treat natural disasters as focusing events in the policy making process. To be more specific, there are many policy issues to be addressed and certain issues surface and expand, such that they lead to rule making, bill passing or policy implementation, while other do not. In this sense, focusing events are key factors in public agenda-setting "where problems and alternative solutions gain or lose public and elite attention." (Birkland 
1997). This is a crucial point since not all issues can be addressed at one time, and the concept of focusing events helps to facilitate an understanding of the diverse and often conflicting forces operating beneath the surface of each issue.

Natural disasters like hurricanes, typhoons and earthquakes are particularly damaging and harmful. They usually result in disaster relief, building improvement projects, risk assessment and hazard-mitigation programs and research and planning projects. In contrast and despite their increasing frequency, severity and impact, long range-transport dust storms from Mainland China to Taiwan are far from being heralded as disasters.

\subsection{Identifying and Framing Dust Event Issues}

Dust storm issues are gradually being "reframed" as dust events (Sha Chen Shi Jian) or dust episodes. The phrase "dust storms invading Taiwan" was used to described dust storms that "reached" Taiwan. However now, when a particular dust event reaches Taiwan, it is "reframe" as a "dust event affecting Taiwan." This shift from damage-loaded storms to natural events was reflected in the findings of the IMP research project. This conceptualization of dust storms allows for comprehensive planning and policy design if in the future these natural "events" turn into "focusing events" as in the case of disasters.

Taiwan needs to cultivate a culture, which acknowledges the damage caused by the effect of dust events and takes it seriously. The phenomenon of dust events in Taiwan lacks the focus, visibility and obvious damage, of an earthquake or typhoon, and yet the long-term effects are unknown.

\subsection{Kingdon's Policy Stream Approach}

The Policy Stream Approach (Fig. 11) proposes that policy will only come about when a "Policy Window of Opportunity" has been created. This "window of opportunity" is opened by combination of three factors: recognition of the problem, a tenable proposal and political support.

\subsubsection{Applying Kingdon's Model of the Policy Stream Approach}

Applying Kingdon's Policy Stream Approach model, the problem of dust events does not meet the criteria because of a lack of recognition for most of the year (Lee 2004). Dust storms only attract media attention when the dust event is particularly severe. Since there is no immediate loss of human life, quantifiable damage or measured financial cost, the coverage is minimal.

Proposals for dealing with dust events will only be considered when the environmental and public health problems they cause Taiwan are recognized and the storms are no longer simply positioned as "natural phenomenon" as they are at present. Until the effects of dust storms are placed high on the political agenda, individuals will not recognize the importance of contributing toward a new policy. Undoubtedly, innovative grading systems and monitoring mechanisms have facilitated proposals to move the issue up the scientific agenda, however, there is still a desperate need to create and implement new policy regarding dust storm events. By studying the events in more detail and highlighting the significance of these annual 


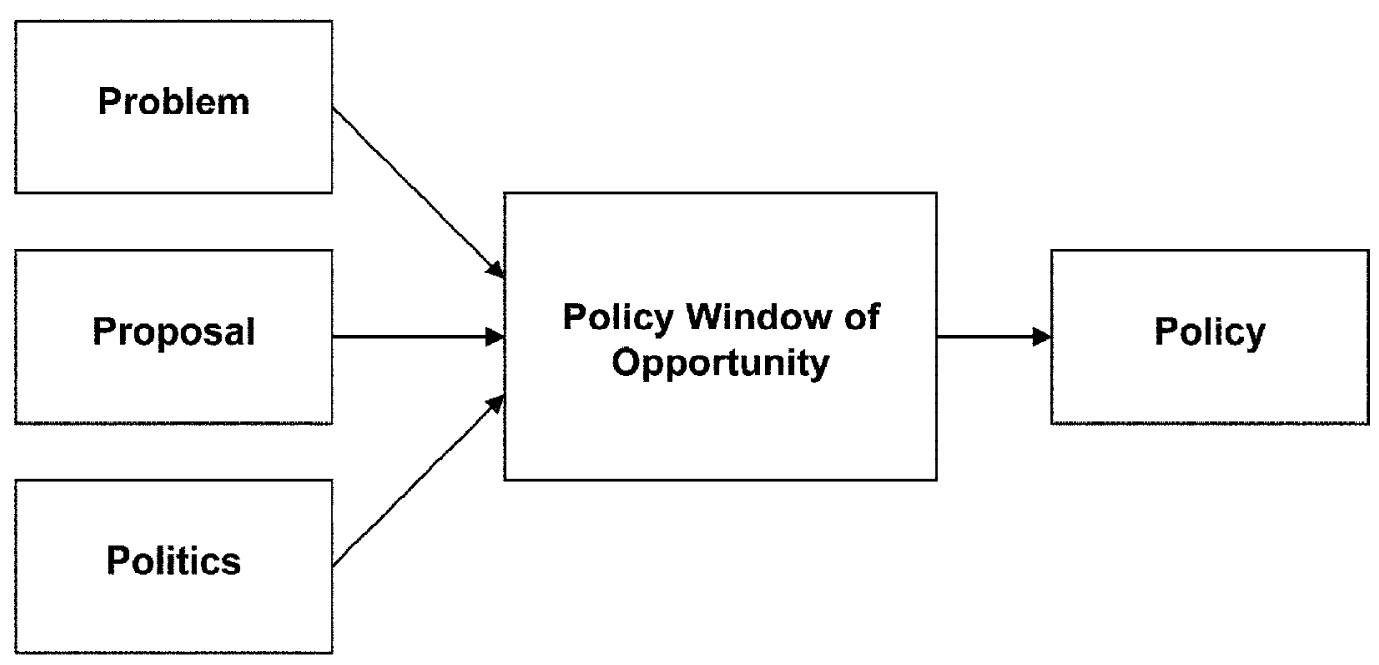

Fig. 11. Kingdon's policy stream approach.

occurrences, it is hoped that new agendas will create a window of opportunity, which opens the way to policy development and implementation.

\subsection{Monitoring Guidelines and Procedures}

Table 3 depicts the current policy guidelines and implementation procedures used for dust storms and governed by the jurisdiction of the Department of Environmental Monitoring and Information Management and the Department of Air Quality Protection of the EPA.

At each stage, tasks are allocated to either observation teams or modeling and forecasting teams, or a combination of the two. Observations are generally collated from remote sensing facilities such as monitoring stations and satellite imaging.

The procedure begins with a standard Monitoring Stage. The Alert Stage is reached when a dust storm event is identified in Mainland China. If, after the data has been collated and modeled, the dust storm is forecasted to affect Taiwan, then the Monitoring and Observation Stage is reached and a Command Center established. If the event is not forecasted to affect Taiwan, the teams return to the Monitoring Stage.

For the duration of the event the Monitoring and Forecasting Team, Scientific Management Team and Administrative Support Team work together to monitor and analyze data from the event. At this time, the Health Impact Assessment team also starts an impact analysis study.

When the dust storm is observed to be dissipating, the procedure moves to the Monitoring and Observing Operation Ending Stage. Once the teams have confirmed the event has ended, the Command Center is dismissed and intensive monitoring is concluded. Finally the case data 
Table 3. Dust Storm events monitoring procedures.

\begin{tabular}{|c|c|c|c|}
\hline Monitoring Level & Operation Tasks & Task Details & Teams Involved \\
\hline Monitoring Stage & $\begin{array}{l}\text { Is there any dust storm } \\
\text { event occurring in } \\
\text { Mainland China? } \\
\text { If yes, go to Alert } \\
\text { Stage. }\end{array}$ & $\begin{array}{l}\text { 1. Analyze weather data } \\
\text { 2. Perform weather model } \\
\quad \text { simulation } \\
\text { 3. Analyze ground-station data }\end{array}$ & $\begin{array}{l}\text { Forecast \& Model } \\
\text { Development Team }\end{array}$ \\
\hline Alert Stage & $\begin{array}{l}\text { Is the dust storm event } \\
\text { approaching Taiwan? } \\
\text { If yes, go to Monitoring } \\
\text { and Observing Stage } \\
\text { Otherwise, go to } \\
\text { Monitoring Stage }\end{array}$ & $\begin{array}{l}\text { 1. Analyze weather data \& } \\
\text { perform weather model } \\
\text { simulation } \\
\text { 2. Analyze ground-station data } \\
\text { 3. Analyze satellite data } \\
\text { 4. Analyze air quality data } \\
\text { 5. Alert Monitoring Team and } \\
\text { Health Impact Analysis Team on } \\
\text { standby } \\
\text { 6. Start radar and satellite } \\
\text { observations }\end{array}$ & $\begin{array}{c}\text { 1. Forecast \& } \\
\text { Model } \\
\text { Development Team } \\
\text { 2. Scientific } \\
\text { Management Team } \\
\text { 4. Administration } \\
\text { Support Team }\end{array}$ \\
\hline \multirow[t]{4}{*}{$\begin{array}{l}\text { Monitoring and } \\
\text { Observing Stage }\end{array}$} & $\begin{array}{l}\text { Establish Command } \\
\text { Center }\end{array}$ & $\begin{array}{l}\text { 1. Start intensive monitoring } \\
\text { 2. Control various teams and } \\
\text { distribute latest data. }\end{array}$ & $\begin{array}{l}\text { Administration } \\
\text { Support Team }\end{array}$ \\
\hline & $\begin{array}{l}\text { Start intensive } \\
\text { Monitoring }\end{array}$ & $\begin{array}{l}\text { 1. Monitoring Team records } \\
\text { data } \\
\text { 2. Health Impact Analysis Team } \\
\text { starts impact analysis }\end{array}$ & $\begin{array}{l}\text { 1. Monitoring Team } \\
\text { 2. Health Impact } \\
\text { Assessment Team }\end{array}$ \\
\hline & $\begin{array}{l}\text { is the dust storm event } \\
\text { approaching Taiwan? } \\
\text { If yes, go to next step } \\
\text { Otherwise, go to } \\
\text { Monitoring Stage }\end{array}$ & $\begin{array}{l}\text { 1. Analyze weather data \& } \\
\text { perform model slmulation } \\
\text { 2. Analyze ground-Station data } \\
\text { 3. Start satellite monitoring } \\
\text { 4. Start air quality monitoring } \\
\text { 5. Start radar and satellite } \\
\text { monitoring }\end{array}$ & $\begin{array}{c}\text { 1. Forecast \& } \\
\text { Model } \\
\text { Development Team } \\
\text { 2. Scientific } \\
\text { Management Team } \\
\text { 3. Administration } \\
\text { Support Team }\end{array}$ \\
\hline & $\begin{array}{l}\text { Record dust storm } \\
\text { ending time }\end{array}$ & $\begin{array}{l}\text { 1. Analyze weather data \& } \\
\text { perform model simulation } \\
\text { 2. Analyze ground-Station data } \\
\text { 3. Start satellite monitoring } \\
\text { 4. Start alr quality monltoring } \\
\text { 5. Start radar and satellite } \\
\text { monitoring } \\
\end{array}$ & $\begin{array}{c}\text { 1. Forecast \& } \\
\text { Model } \\
\text { Development Team } \\
\text { 2. Scientific } \\
\text { Management Team } \\
\text { 3. Administration } \\
\text { Support Team } \\
\end{array}$ \\
\hline \multirow[t]{4}{*}{$\begin{array}{l}\text { Monitoring and } \\
\text { Observing } \\
\text { Operation Ending } \\
\text { Stage }\end{array}$} & $\begin{array}{l}\text { Is the dust storm } \\
\text { ending? }\end{array}$ & $\begin{array}{l}\text { 1. Analyze weather data \& } \\
\text { perform model simulation } \\
\text { 2. Analyze ground-Station data } \\
\text { 3. Start satellite monitoring } \\
\text { 4. Start air quality monitoring } \\
\text { 5. Start radar and satellite } \\
\text { monitoring }\end{array}$ & $\begin{array}{c}\text { 1. Forecast \& } \\
\text { Model } \\
\text { Development Team } \\
\text { 2. Scientific } \\
\text { Management Team } \\
\text { 3. Administration } \\
\text { Support Team } \\
\end{array}$ \\
\hline & $\begin{array}{ll}\text { Dismiss } & \text { Command } \\
\text { Center } & \end{array}$ & End intensive monitoring & $\begin{array}{l}\text { Administration } \\
\text { Support Team }\end{array}$ \\
\hline & Case Study & Case data analysis & $\begin{array}{l}\text { 1. Scientific } \\
\text { Management Team } \\
\text { 2. Administration } \\
\text { Support Team } \\
\text { 3. Forecast \& } \\
\text { Model } \\
\text { Development Team } \\
\text { 4. Monitoring Team }\end{array}$ \\
\hline & $\begin{array}{l}\text { Caso Ended, go back } \\
\text { to Monitoring Stage }\end{array}$ & & \\
\hline
\end{tabular}


is analyzed by the respective teams, with the Monitoring Stage re-implemented until detection of another dust storm event is registered on the Mainland.

\subsection{Current Project Management Infrastructure}

Currently there are a total of five teams, who are involved in the complete dust storm monitoring procedure, and a hierarchical infrastructure oversees their functions and procedures. The roles and organization of these teams and the role of the EPA, as the umbrella organization responsible for the IMP project, are illustrated in Fig. 12.

3.5.1 The Forecast \& Model Development Team is responsible for performing the computer model simulation of a dust storm and providing the future moving trend of the storm. The team is also responsible for fine tuning the mathematical model used to simulate the dust storm in order to provide more accurate forecasts.

3.5.2 The Monitoring Team is responsible for monitoring the progress of an active dust event and serves as the source of all monitored data on the dust event.

3.5.3 The Health Impact Assessment Team is responsible for assessing the impact of the active dust event on people's health in Taiwan.

Fig. 12. Monitoring team hierarchy.

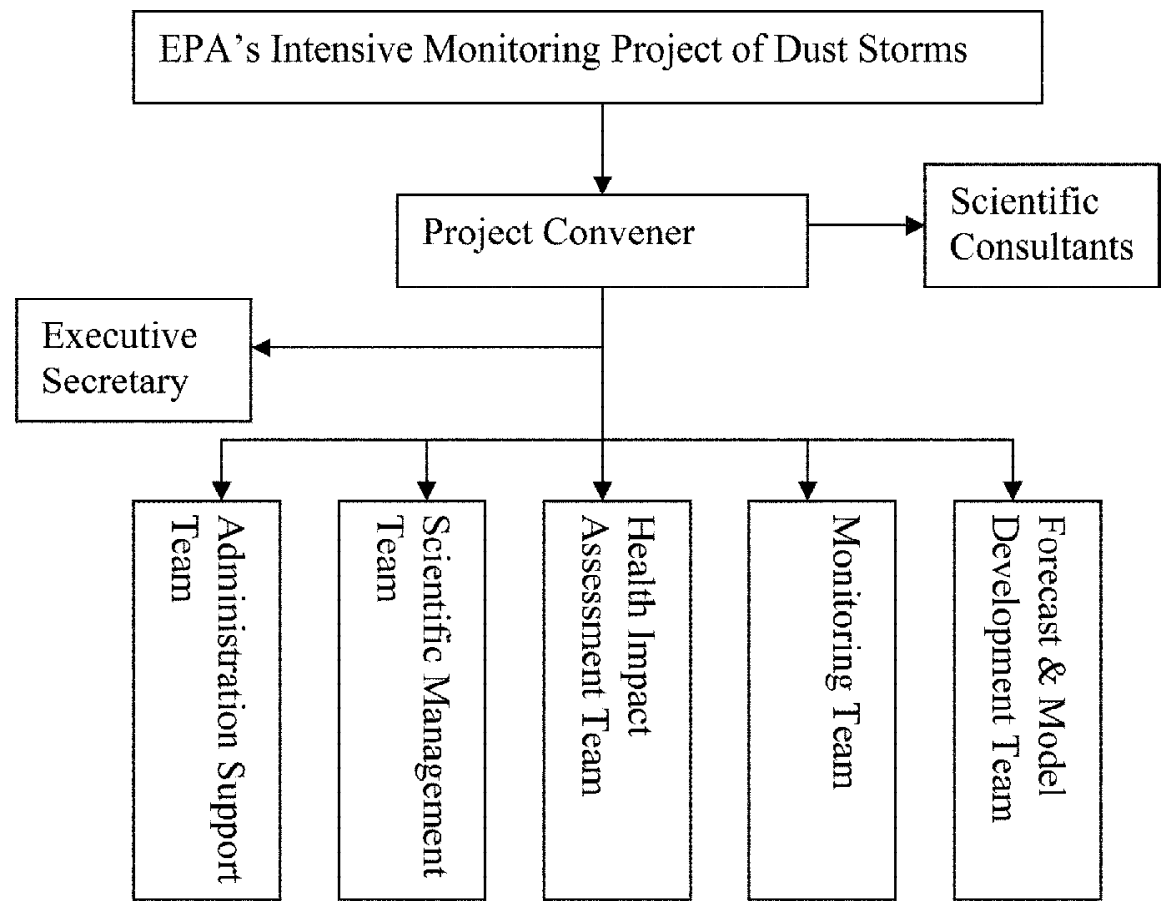


3.5.4 The Scientific Management Team is responsible for coordinating project management and compiling all the data collected during dust episodes to form a conclusive report at the end of the project study.

3.5.5 The Administration Support Team is responsible for performing any administrative tasks necessary to support the project.

3.5.6 Finally, the Vice Minister of the EPA serves as the Project coordinator. To this end, the secretariat is situated at the department of Environmental Monitoring and Information Management (EMIM) and the EMIM director acts as the executive secretary to oversee the entire project.

\subsection{Unresolved Issues and Recommendations}

As discussed earlier, the EPA sponsored IMP has been conducting research for three years since 2001. There are encouraging and promising research results in model simulations (Chen et al. 2004) in air quality studies (Lin et al. 2004; Chou et al. 2004) and composite research (Liu et al. 2004; EPA 2001; Liu et al. 2001). Nevertheless, research findings are still preliminary, and the monitoring and measurement technology is still to be developed further. Most of all, impact studies such as health impact assessments have to be expanded. Initiating more research is, in essence, building the foundation for better understanding and forecasting of future events. Confronted with various unresolved issues relevant to dust events, a set of recommendations for implementation is listed below.

\section{REFRAMING CRITICAL ISSUES}

Dust storms are now viewed more as natural events than as natural hazards. They constitute important but not urgent issues in the policy making process. In other words, they do not qualify as focusing events, demanding urgent attention and hasty policy responses, at this time.

Unlike hurricanes, landslides and earthquakes, dust-episodes are now framed as natural phenomena instead of natural disasters. The main reason is that dust episodes occur less frequently compared to hurricanes and landslides, and they cause less obvious damage. Since they receive less media attention, dust episodes are not considered focusing events and are not deemed to require an immediate policy response.

This does not mean that dust episodes should be ignored. In fact a shift in paradigm is needed in the approach that is taken to these events and in the values by which these events are graded. The long term impact of air quality, on the health and environment must also be monitored and evaluated.

The research done so far shows that dust episodes are increasing in their severity and frequency. Consequently, more research should be done to monitor the future trend of dust episode events, and hopefully appropriate actions can be taken before they become disastrous focusing events. 


\section{BROADENING THE RESEARCH AGENDA}

Put simply there is a desperate need to obtain more baseline data for analysis. There is also need to conduct more research on the effects of dust storms in Taiwan. The on-going research project was a good start but even more impact studies are needed, as are policyrelevant research studies, like this one. Altogether, more research and impact studies are definitely needed to help researchers take a better look at the problem and to develop strategic plans to better manage the effects of future dust episodes.

\subsection{Public Health Implications}

So far, only one preliminary impact study on public health (Chao and Chan 2003) has been undertaken. This impact study only examined the impact on public health, several days after a dust event and concentrated on two hospital emergency rooms admission records. The results of the study require further analysis to distinguish between the effects of local air pollution and that derived from remote sources.

Available data covers the short-term impact of dust storms on public health. However there is also a need to engage in studies on the long-term effects. The research in this field needs to be significantly broadened to obtain an accurate picture of the influence of dust storm events on public health.

\subsection{Bio-Aerosols}

There is a need for more data regarding the presence of bio-aerosols in airborne dust particles. The preliminary data available is not sufficient to provide a comprehensive picture of the effect dust storms on public health and ecology of Taiwan. It is very difficult to distinguish between local and remote contributions from the impact records obtained so far. To worsen the situation, distinguishing between different forms of air-pollution sources, such as forest fires, local biomass burning and dust storms, has also proven difficult. More studies need to be carried out and close attention paid to the work of others in this field.

There is a need to change the approach to air quality monitoring, measure and management to consider the effects of biomass burning, both in Taiwan and in overseas countries, such as Indonesia, especially as this traditional element of agricultural practice is often carried out in November and December. Since the future here is unclear, this potential hazard warrants immediate attention and inclusion in the research agenda.

\section{COORDINATING INSTITUTIONAL ADMINISTRATION}

\subsection{Inter-departmental Coordination}

Two departments are involved in the organizational structure of the EPA, namely, the Department of Air Quality Protection and Noise Control and the Department of Environmental Monitoring and Information Management. The IMP is also managed by these two 
departments. Closer interaction, cooperation and coordination between these two departments are needed. In particular, the Department of Air Quality Protection should be involved in the implementation of policies and more involved as a joint and equal partner in the process of actively monitoring the effect of dust storms in Taiwan.

\subsection{EPA/CWB Coordination}

Coordination between the EPA and other agencies, such as the Central Weather Bureau and those overseeing national hazard mitigation projects, would help facilitate better policy. Close interaction between these agencies would promote careful and efficient planning in and for the future. Hopefully, this interaction would mitigate rivalry between agencies and so the need to be the "lead" agency in relation to project management and funding decisions.

One possible solution would be to create a task force to deal with dust storms in much the same way as a task force is created seasonally, from April through to October, to deal with typhoons. If necessary, the task force could be "ad hoc", but would need to be able to instill a culture of inter-departmental cooperation at the ministerial level, when dealing with this important issue. The view that a task force is not needed in the absence of a typhoon-like "disaster", negates the significance of the problems presented by poor air quality and dust storms. To regulate the importance of these issues in the political agenda a cooperative group is necessary.

\subsection{Scheduling}

The schedule for EPA funding for dust storm studies is detrimental to the collection of data itself. Certain project funding does not begin until March 15 and all too often the most vital months for this type of study, January and February, are missed. In January there was a particularly severe event that was not monitored due to a lack of funds. Approximately $60 \%$ of dust storms reach Taiwan from January to April and so administrative flaws such as delayed funding can be devastating and counterproductive to research projects.

Research into dust storms should be taken seriously and a specific project team created to monitor the effects of dust storms. This should be an ongoing concern, rather than an annual project. Dust storms, despite the occasional lull in their intensity are not going away and evidence points to their increased frequency and affect on Taiwan. It is critical that funding for research is, at the very least, available well before "dust event season" in order to prepare monitoring teams, personnel and equipment. The ability to conduct ongoing and regular monitoring will greatly improve our ability to understand and cope with the effects of dust events in Taiwan.

\subsection{Applying the Precautionary Principle}

"Long-term natural events", such as those presented by dust storms cannot be resolved using a "short-term crisis management" model. For instance, 2003 happen to be a "mild"year for dust storms ( 5 episodes, 6 days for Level 1, and only 1 day for Level 2) and researchers were alerted to draft a "careful and proper" conclusion since the impact was relatively "minimal". Instead of feeling "disappointed," this was an opportunity to feel grateful that Taiwan was 
afforded a mild year for dust storms. The precautionary principle should be used as a "no regret" policy approach to better prepare for the future. For every dust event affecting Taiwan, standard and complete measurements should to be conducted, regardless of the level of severity. That is, each event must be taken seriously.

The on-going monitoring process is of significant benefit, even if the results are "mild". Funding of this monitoring, when the intensity and frequency of dust events is low, should be considered a good investment for the future. This position is supported by the Rio Declaration, on global warming phenomena, which states, "lack of full scientific certainty" should not be used as an excuse for "postponing cost-effective measures to prevent environmental degradation" (Rio Declaration, Principle 15, quoted in Susskind 1994 ). Ignoring "mild" dust events only contributes to ignorance and an inability to accurately predict and deal with severe dust events in the future.

\section{ENHANCING REGIONAL/INTERNATIONAL COOPERATION}

\subsection{ASEAN Regional Model}

There are both local and foreign sources of pollution. No single country can deal with global environmental issues alone. The case for a regional model is based on ASEAN's fight for a Haze and Zero-burning policy. Their regional approach encourages local and international coordination between relevant institutions. It has further created a comprehensive monitoring network for the specific analysis of the phenomenon and established a clearly defined alert status. ASEAN has also taken advantage of web-based coordination strategies and established regional research teams. There is much to be learnt from ASEAN's proactive regional approach and a similar approach should be applied to dust storm events.

\subsection{Bi- and Multi-lateral Treaties}

Neighboring countries can work together at a governmental level to promote a more coordinated strategy in coping with dust storms. Bi-lateral treaties signed by China and Outer Mongolia to combat dust storms, a pressing problem for both countries, can be used as a model for co-operation. These two countries have agreed to carry out a comprehensive monitoring program, fund and implement seeding to create more grassland (theoretically reducing dust levels) and reduce over-grazing in threatened areas. By actively participating in such treaties, Taiwan could ensure closer coordination with overseas efforts and a more effective method to deal with the issue.

\subsection{Coordinated Monitoring Strategy}

The monitoring of sandstorms could be done efficiently and swiftly if cooperative regional relationships were cultivated. If it were found that the majority of Taiwan's air pollution did not come from local sources, a mechanism for regional and international cooperation would definitely be necessary to fight non-local air pollution. 
Both research efforts and planning should be long term. In terms of policy, the current procedures and guidelines appear to be effective, although there is room for improvement in the coordination of institutional arrangements. Research findings of the IMP are reasonably useful in the policymaking process. Impact studies are more effective over a longer period of time. To ensure comprehensive planning, strategic choices need to be made, the potential of impact studies must be considered and the importance of regional and international cooperation stressed.

\section{REFERENCES}

Birkland, T. A., 1997: After disaster: Agenda setting, public policy, and focusing events, Washington, DC, Georgetown Univ. Press.

Chan, C. C., 2002: Project report on China dust storms health impacts to residents in Taiwan, EPA-91-FA11-03-D036.

Chao, H. J., and C. C. Chan, 2003: The study of dust storm and background aerosol biological composition, EPA-92-U1L1-02-101.

Chen, J. P. et al., 2004: Simulations of Asian yellow dust incursion over Taiwan for the spring of 2002 and 2003. TAO, 15, 949-981.

Chou, C. C. K., et al., 2004: Influence of long-range transported dust particles on local air quality: a case study on the Asian dust episodes in Taipei during the spring of 2002. TAO, 15, 881-889.

Environmental Protection Administration, 2001: Conference proc. Mainland China's dust storms' impact to air quality in Taiwan, Taipei, March 12, 2001.

Kingdon, J. W., 1995: Agendas, alternatives, and public policies, New York, Harper Collins College Publishers.

Lee, H. C., 2004: The air quality impacts of long-transported dust storm events in Taiwan: a policy stream approach. J. Arid Land Resources Environ., 18, 149-152.

Lee, H. C., 2004: Negotiating Climate Change: The Role of Science and Its IR Implication. Issues and Studies, Nov/Dec Issue (forthcoming).

Lin, C. Y. et al., 2004: Long-range transport of Asian dust and air pollutants to Taiwan.TAO, 15, 759-784.

Liu C. M. et al., 2001: Dust storm intensive monitoring project report. Environ. Protec. Administration, ROC.

Liu, C. M., and H. C. Lee, 2003: Integrated Project Report on Monitoring Dust Events, EPA92-FA11-03-B007.

Liu, C. M. et al., 2004: A composite study of the synoptic differences between major and minor dust storm springs over the China-Mongolia areas. TAO, 15, 999-1018.

Liu, C. M., 2003: Integrated analysis of Mainland china dust storm events affecting air quality in Taiwan, 1994 - 2003, Workshop on long range transportation impacting on Taiwan air quality in the spring season, Taipei. November 19, 2003. 
Mitchell, R. B. et al. (Eds.), 2005: Global Environmental assessments: information, institutions and influence. MIT Press.

Susskind, L. E., 1994: Environmental diplomacy: Negotiating more effective global agreements, Oxford, UK: Oxford Univ. Press.

\section{Notes}

1. Most of the background information on the dust storms in China is adopted from the EPA web information available online at http://ivy2.epa.gov.tw/gepp/page01.htm.

2. The level of dust storms was first suggested by the science management team and then adopted by the other research teams at the mid-term review meeting on July 8, 2003.

3. Mid-term status report, on intensive monitoring project on Mainland China's dust storms, July 2003.

4. Implementation Handbook on intensive monitoring project on Mainland China's dust storms, online at http://cats.as.ntu.edu.tw/weather/envi/. 